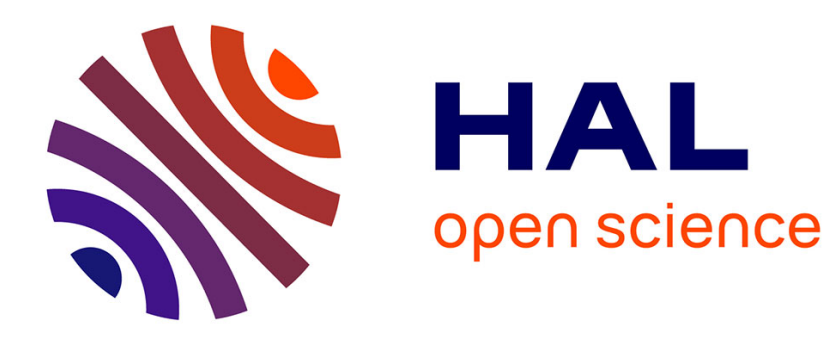

\title{
Cytoplasmic domains in eggs
}

\author{
Christian Sardet, Alex Mcdougall, Evelyn Houliston
}

\section{To cite this version:}

Christian Sardet, Alex Mcdougall, Evelyn Houliston. Cytoplasmic domains in eggs. Trends in Cell Biology, 1994, 4 (5), pp.166-172. 10.1016/0962-8924(94)90201-1 . hal-03025639

\section{HAL Id: hal-03025639 \\ https://hal.science/hal-03025639}

Submitted on 16 Dec 2020

HAL is a multi-disciplinary open access archive for the deposit and dissemination of scientific research documents, whether they are published or not. The documents may come from teaching and research institutions in France or abroad, or from public or private research centers.
L'archive ouverte pluridisciplinaire HAL, est destinée au dépôt et à la diffusion de documents scientifiques de niveau recherche, publiés ou non, émanant des établissements d'enseignement et de recherche français ou étrangers, des laboratoires publics ou privés. 
36 WOLD, M. S., II, I. I. and KELLY, T. J. (1987) Proc. Natl Acad. SCi. USA 84, 3643-3647

37 ADACHI, Y. and LAEMMLI, U. K. (1992) J. Cell Biol. 119, 1-15

38 LENO, G. and LASKEY, R. A. (1991) /. Cell Biol. 112, 557-566

39 MIYAKE, S. et wil. (::393) Mol. Biol. Cell 4, 1003-1015

40 LOHKA, M. J. and MALLER, I. L. (1985) J. Ceil Biol. 101, 518-523
41 D'URSO, G., MARRACCINO, R. L., MARSHAK, D. R. and ROBERTS, J. M. (1990) Science 250, 786-791

42 HU, B., BURKHART, R., SCHULTE, D., MUSAHL, C. and KNIPPERS, R. Nucleic Acids Res. (in press)

43 COXAN, A., MAUNDRELL, K. and KEARSEY, S. (1992) Nitcleic Acids Res. 20, 5571-5577

\section{Cytoplasmic domains in eggs}

\author{
Christian Sardet, Alex McDougall \\ and Evelyn Houliston
}

One way of organizing the body plan of a developing embryo is to establish domains in the egg with distinct compositions in defined spatial relationships to one another: when the egg divides up, these domains segregate preferentially to certain regions of the embryo and influence their development. In this review we discuss the nature, formation and reorganization of distinguishable domains

in various eggs.

The authors are at

the Unité de

Biologie Cellulaire

Marine (URA 671),

Centre National

de la Recherche

Scientifique and

Université

P. et M. Curie (Paris VI),

Observatoire,

Station

Zoologique,

Villefranche-sur-

Mer 06230,

France.
Different reglons of the eggs of many animals are characterized by concentratlons of partlcular organelles, such as plgment granules, mitochondrla and ER, or exclusion of yolk platelets. These vistble egg domains have been studled principally in insects (Drosophila), amphibians (Xenopus), ascidians (Styela and Phallusia), sea urchins and nematodes (Caenorhabditis), where their fate can be followed and/or their role in development tested by transplantation and ablation. Typic" 'ly, egg domains are established in oogenesis in relation to the developing polarized oocyte structure, and are reorganized during oocyte maturation and following fertillzation. This article concentrates on a comparison of cytoplasmic domains in different species during these early stages of development. The localization of mRNAs and proteins to particular domains and the role of cytoskeleton components in their organization have been discussed in recent reviews ${ }^{i-3}$.

\section{Establlshment of tumains in oocytes}

The extent to which organizational asymmetry is established during oogenesis varies between animals (see Refs 4 and 5 for general discussions). In Drosophila, cytoplasmic and extracellular components become localized aiong two axes in the oocyte, corresponding to the future anteroposterior and dorsoventral axes of the embryo ${ }^{6}$, and there is little shuffling of cytoplasmic domains following fertilization. By contrast, in amphibian and ascidian oocytes (Fig. 1 Ia and Ila), distinct domains are established about a single 'animal-vegetal' axis, in a radial arrangement ${ }^{7,8}$, and sperm entry triggeis important reorganizations. Other oocytes apparently have no domains relating to future embryo organization. In the mouse, for instance, cell interactions and cytoplasmic movements starting at the eight-cell stage are entirely responsible for patterning the embryo.

In Drosophila, the polarized organization of the oocyte arises during oogenesis as a result of its asymmetric spatial relationship with the cells surrounding it. There is only one obvious specialized cytoplasmic domain in the oocyte, a yolk-free region at the posterior end known as pole plasm ${ }^{9.11}$. Other, 'invisible' localizations of specific proteins and mRNAs at the anterior and posterior poles are responsible for inItlating a chain of events that determine the different fates of cells along the anteroposterior axis of the embryo ${ }^{5,6}$. Pole plasm contains polar granules (ribonucleoprotein-rich bodles) assoclated with an accumulation of mitochondria, and is later inherited by certain 'pole cells', which found the germ line. A number of specific pole plasm components have been identifled. A key component for the process of germ-plasm localization is oskar mRNA: its mislocalization causes other pole-plasm components to accumulate at the ertopic site and ultimately pole cells to form there". Distinct cytoplasmic domains with a. .milar appearance and function to pole plasm have teeun described in a wide range of organisms as 'germ plasm' and showr to contain germ-rell determinants ${ }^{9,10}$. Furthermore, antibodies recognizing an RNA.binding protein in Drosophila polar granules detect germ-plasm components in Xenopus, suggesting that the molecular basis of germ-line determination may be conserved ${ }^{12}$. Mitochondria, which are characteristically associated with germ plasm and have tightly associated mitochondrial large ribosomal RNA, may also cuntribute to the determinant properties of germ plasm ${ }^{13}$.

In Xenopus oocytes, germ plasm is associated with intermediate-filament proteins in the vegetal corte ${ }^{7}$. 
It arises from a 'mitochondrial cloud' that moves from the centre of the oocyte to the vegetal cortex early in oogenesis. Patches of germ plasm spread from the cortex into the cytoplasm to form distinct islands during the hormonally triggered completion of meiosis. As in Drosophila, these are characterized by dense, RNA-containing 'germinal granules' and accumulations of mitochondria. The vegetal cortex also harbours specific mRNAs ${ }^{1}$, whose protein products include growth factors and RNA-binding proteins. These are presumed to play roles in later development, although none has yet been demonstrated. Like the localized mRNAs in Drosophila ${ }^{14}$, they appear to use the polarized oocyte microtubule network to reach their final destination, where they may attach to cortical microfilaments or intermediate filaments. Differences in the timing of arrival and attachment of the different localized vegetal components suggest that several translocation and anchorage mechanisms operate. Another clearly recognizable domain in the Xenopus oocyte is established in the animal hemisphere during meiotic maturation ${ }^{15}$ (Fig. 1 la). This 'yolk-free domain' is rich in RNA and contains filamentous and vesicular elements, inheriting some of the nuclear contents as well as distinct material from around the base of the nucleus.

In ascidians, the contents of the oocyte nucleus also contribute to the formation of a large domain of cleai animal cytoplasm. This 'ectoplasm' contains endoplasmic reticulum (ER), ribosomes, glycogen granules and fine fllaments. Ascidian oocytes contain other visible domains, including 'myoplasm', present in a subcortical layer interrupted at ihe animal pole ${ }^{8}$ (Fig. 1 Ila). The myoplasm consists of a dense accumulation of mitochondria, an intermediate filament network and, in some species, pigmented vesicles. It appears to assemble during oogenesis from an accumulation of pigmented vesicles and mitochondria very reminiscent of the amphiblan mitochondrial cloud, and from an intermediate-filament network that develops beneath the microfllament-rich cortex $^{16}$. Myoplasm is thought to contain determinants for the formation of muscle in the tadpole tail ${ }^{16,17}$. Myoplasm is extensively modified or entirely absent in various species that do not develop into tadpole larvae with functional muscle cells ${ }^{16}$.

\section{Immediate responses to egg activation}

The immediate reorganizations of the egg cortex and cytoplasm that occur in response to egg activation (by fertilization, egg laying or parthenogenesis) appear mainly to be direct or indirect consequences of a transient increase in egg cytoplasmic $\mathrm{Ca}^{2+}$. At fertilization, this occurs as a wave of $\mathrm{Ca}^{2+}$ release from internal stores (mainly ER) into the cytoplasın, propa. gating from the site of sperm-egg fusion ${ }^{18}$. The $\mathrm{Ca}^{2+}$ transient triggers a wave of cortical reorganization, including the exocytosis of submembranous vesicles called cortical granules (Fig. 1 la). Fragmentation of the $\mathrm{ER}$ network also occurs at the peak of $\mathrm{Ca}^{2+}$ release $^{19}$.

In sea urchin, as in other eggs, the $\mathrm{Ca}^{2+}$ transient is followed by a wave of actin polymerization and microfilament bundling. Microvilli become erect and there is a transient stiffening of the egg surface in response to the alkalinization of the cytoplasm, a consequence of the activation of $\mathrm{Na}^{+}-\mathrm{H}^{+}$exchange by the $\mathrm{Ca}^{2+}$ transient ${ }^{20,21}$. There is no obvious link between these cortical changes and later patterning of the embryo, but in some sea urchin species vesicles implicated in mRNA binding move into the cortex just after fertilization and are later preferentially released from the cortex of vegetal cells ${ }^{22}$.

In Xenopus eggs, cortical granule exocytosis and eiongation of microvilli spread as a wave from wherever the sperm enters in the animal half (Fig. $1 \mathrm{Ia}$ ). The associated actin-based cortical contraction of the thickened pigmented cortex in the animal hemisphere (Fig. $1 \mathrm{Ib}$ ) appears to be centred around the animal pole, so does not break the radial symmetry of the egg. It brings the male pronucleus closer to the female pronucleus at the animal pole ${ }^{23}$.

In Phallusia, the cortical contraction initiated by the $\mathrm{Ca}^{2+}$ wave is asymmetric, starting first on the side of the egg where the sperm entered ${ }^{24}$ (Fig. 1 Ila and b). This contraction, which constitutes the 'first phase of ooplasmic segregation', involves a basket of cortical actomyosin microfilaments, open at the animal pole ${ }^{25}$. It brings the sperm pronucleus, surface proteins and many cortical components towards a 'contraction pole' located to one side of the vegetal pole, on the opposite side to sperm entry ${ }^{24}$. This asymmetric contraction results in the formation of a new domain, rich in microvilli and ER ${ }^{26}$ (Fig. $1 \mathrm{Ilb}$ ). The subcortical myoplasm domain is also pulled into the contraction pole region. UV irradiation or removal of small amounts of cytoplasm from around the vegetal pole of the Styela egg at this time can inhibit gastrulation, leading to the proposal that nucleic-acid-based axial determinants become concentrated transiently in this region ${ }^{27}$.

\section{Reorganizations during sperm aster growth and migration}

Sperm asters are giant asters of microtubules nucleated by the sperm-derived centrosome. They have been seen in most eggs examined, with the exception of mouse eggs $^{28}$. The microtubules of the sperm asier provide tracks for the female pronucleus to move towards the male pronucleus. Both pronuclei are taken by the growing aster to the centre of the egg (Fig. 1 Ic and d; IIc and d), a movement explained most simply as 'pushing' of growing microtubule ends against the cortex. Certain cytoplasmic organelles and parts of the ER network accumulate with the pronuclei in the center of the aster, while other 

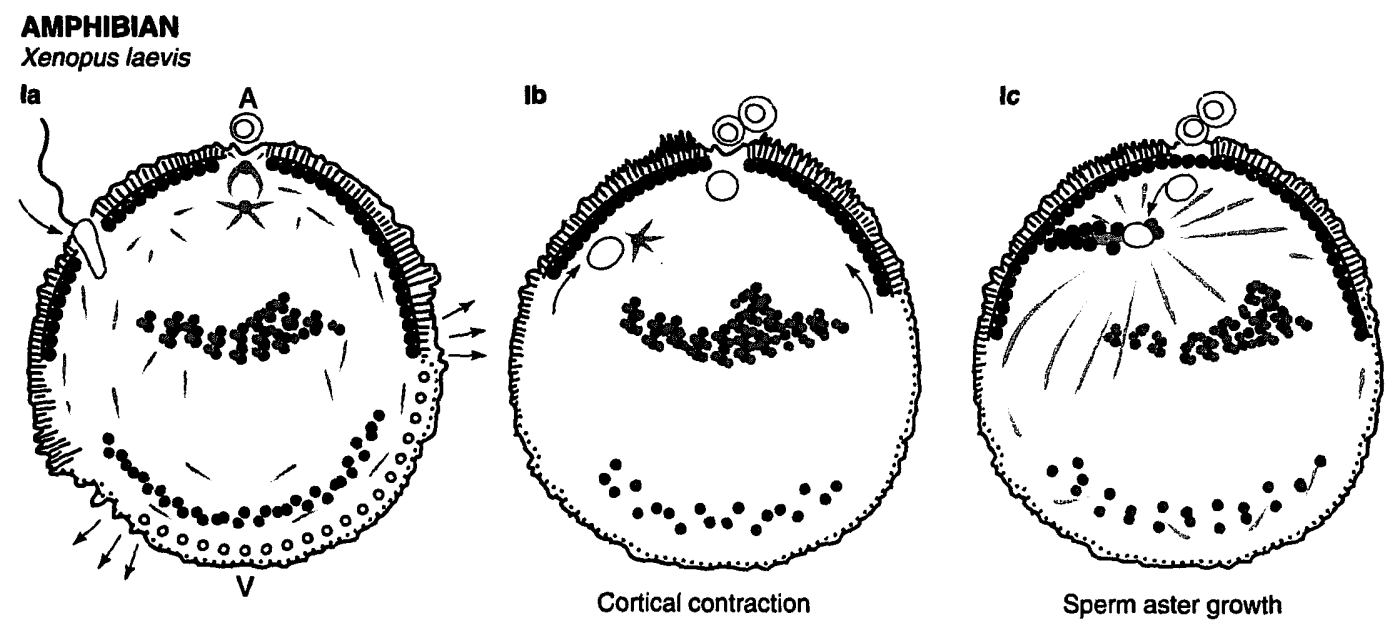

\section{ASCIDIAN}

Phallusia mammillata

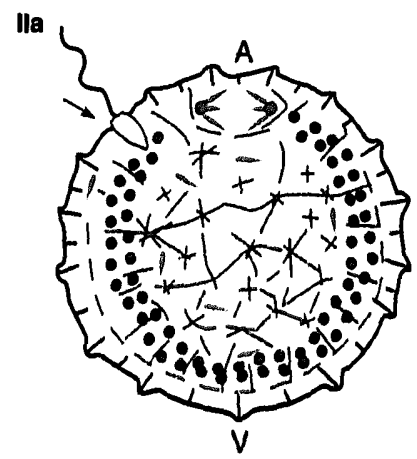

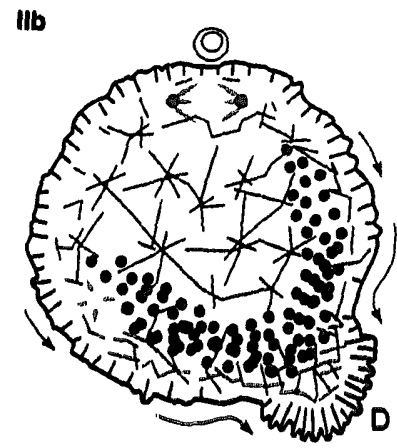

1st phase of segregation

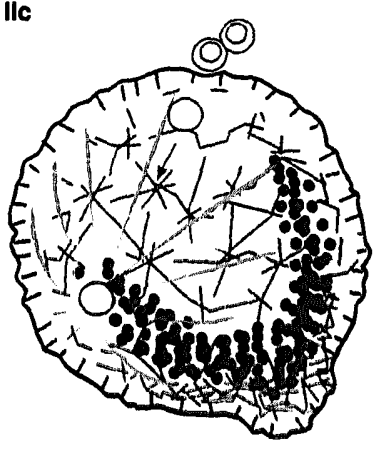

Sperm aster growth

\section{NEMATODE}

Caenorhabditts elegans

IIIa

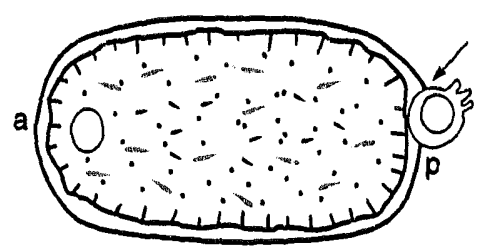

IIIb

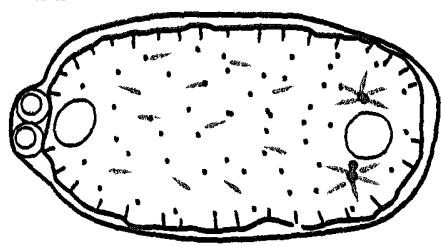

$45 \mathrm{~min}$ after fertilization

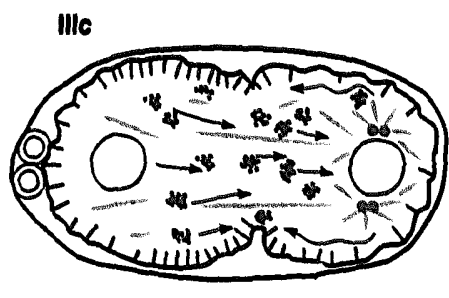

Pseudocleavage

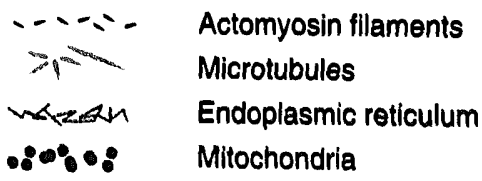

Do (O) 000000

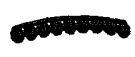

.. . . .
Nucleus, chromosomes, polar body Cortical granules Pigment granules

$P$ granules 
Id

le

(9) Thm?!m?

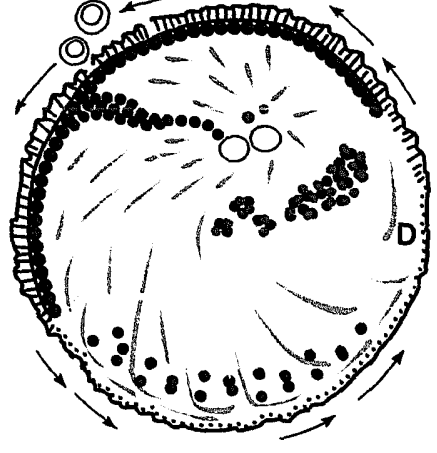

Cortical rotation

IId

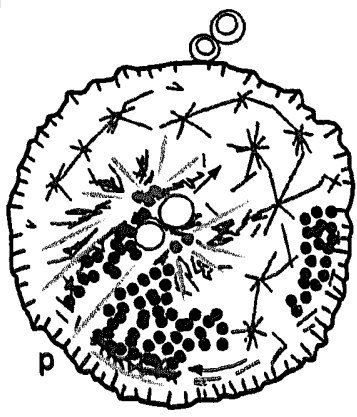

and phase of segregation
Ile

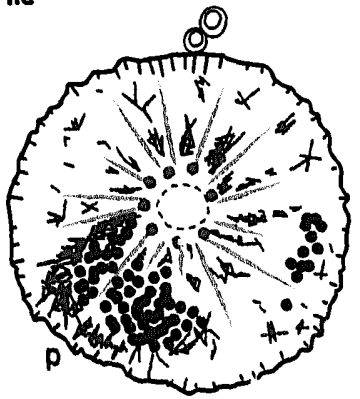

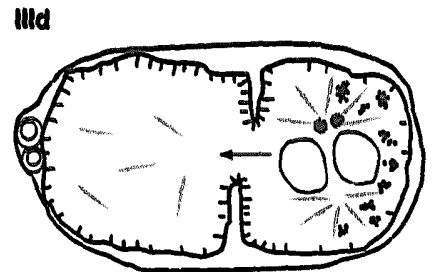

P-granule segregation

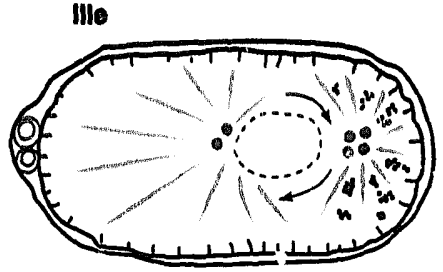

Rotation of nucleus
IIf

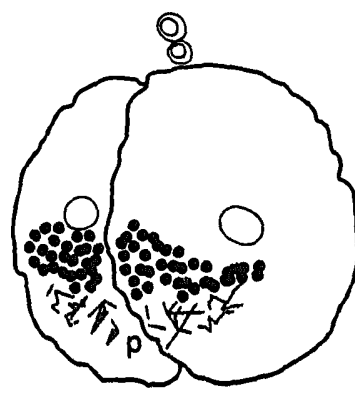

Simplified

3/4 posterior view

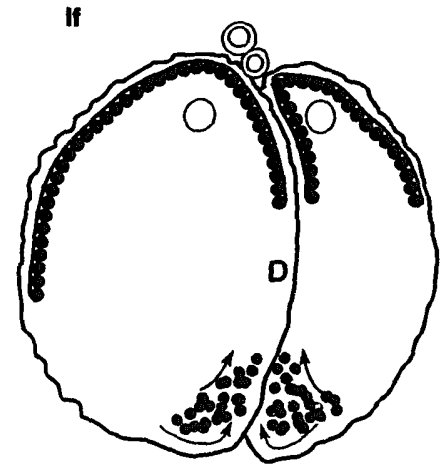

Simplified

3/4 dorsal view

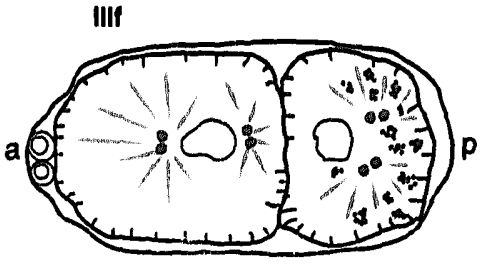

Unequal cleavage

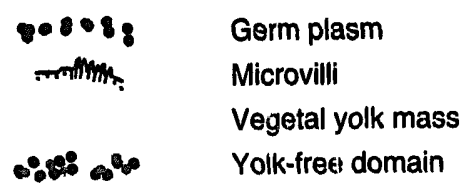
A: animal pole
V: vegetal pole
D: dorsal
a: anterior
p: posterior 
organelles such as yolk granules are excluded. This formation of cytoplasmic domains in relation to the aster presumably results from plus- and minus- enddirected microtubule-based motor activity, both of which are favoured during interphase in isolated Xenopus egg cytoplasm ${ }^{29}$.

In ascidians, reorganizations associated with the sperm aster elaborate the initial asymmetry created by the cortical contraction. The sperm aster grows in the vegetal hemisphere on the side of sperm entry, where the sperm nucleus and associated centrosome have been carried (Fig. 1 IIc). The centrosome flattens and moves to a sub-equatorial region, dragging the bulk of the ER-rich domain with it ${ }^{26,30}$. The myoplasm is also dragged into the migrating aster, 'tearing' at the vegetal pole, to form a crescent of myoplasm marking the future posterior pole of the embryo (Fig. 1 IId and e).

The sperm aster of Xenopus plays an indirect and dispensable role in specifying the dorsoventral axis of the embryo. Microtubules extending from the aster join with an extensive array of aligned microtubules forming beneath the vegetal cortex ${ }^{31}$. This vegetal - :srotubule array appears normally to be oriented by the astral microtubules, but can form in the absence of a sperm aster and can be oriented independently of it by experimental means ${ }^{32,33}$. Normal development can proceed if the sperm aster is eliminated ${ }^{3+}$. The aligned vegetal microtubules provide tracks for the translocation of the vegetal cortex relative to the underlying cytoplasm ${ }^{35}$. During 'cor* tical rotation', the cortex appears to be transported to the plus end of the vegetal microtubules by a kinesin-related motor ${ }^{36}$. The bulk movement of the vegetal cytoplasm relative to the cortex provokes complex swirling of the different domains in the more fluid animal cytoplasm ${ }^{17}$ (Fig. 1 Id), Such relocation of egg components is ultimately responsible for giving dorsal characters (for instance the ability to induce the formation of dorsal mesoderm) to the cells that inherit the equatorial cytoplasm opposite the sperm entry point. Independently of the corticalrotation-induced movements, segregation of yolk granules, cytoplasm and the yolk-free domain in the animal hemisphere occurs on sperm aster microtubules $^{38-410}$. These movements do not appear to influence the establishment of the dorsal region.

In Caenorhabditis, the sperm aster also cues cytoplasmic localizations by indirect means ${ }^{+1}$. A double sperm aster forms at the posterior end of the egg after the sperm has entered there and its centrosome has duplicated (Fig. 1 IIla and b). Germ-plasm-like 'P granules' aggregate and segregate to the posterior pole during a period of cortical movements in the anterior half of the egg and the formation of a central pseudocleavage furrow (Fig. 1 IIIc). It has been proposed that the microtubules of the sperm aster promrit a relaxation of cortical tension at the posterior pole ${ }^{42}$. The ensuing movement of the contractile cortical elements towards the anterior pole would be balanced by the flow of central cytoplasm carrying $P$ granules towards the posterior pole, where they are destined to segregate. This model explains the cytochalasin sensitivity of $P$ granule movement at the time of pseudocleavage furrow formation.

\section{Reorganization during mitosis and cleavage}

The asters of the mitotic spindles can modify the organization of the egg cytoplasm by segregating certain cellular organelles such as ER and yolk vesicles. Directed cytoplasmic movements around the time of mitosis also take place as a result of 'precleavage waves', or 'surface contraction waves' (SCWs). These were described first in amphibian eggs, where they originate at the animal pole ${ }^{43}$. In Xenopus, SCWs cause the islands of germ plasm situated below the vegetai cortex to accumulate around the vegetal pole, by a microtubule-dependent mechanism ${ }^{44}$ (Fig. 1 Ie and $\mathrm{f}$. Similar waves of reorganization, including microtubule-dependent cytoplasmic remodelling, occur before cleavage in the ctenophore Beroe ${ }^{45}$. These waves appear to reflect the localized activation of mitotic factors around the zygote nucleus. The precleavage waves in Beroe occur at the time the single embryonic axis is specified, and run in the direction of this axis; however, no causal link has yet been established.

Exaggerated actin-based surface contractions and deformations at the time of mitosis in many mollusc and annelid eggs result in the formation of 'polar lobes' of varlous sizes near the vegetal pole ${ }^{46}$. At each of the first few cleavages, the polar lobe and its con. tents foin only one cell, allowing their coistituents (distinct vesicles, germ-plasm-like materlal, RNA-rlch cytoplasm) to be segregated, and thus direct the fate of different regions of the embryo. Polar lobe forma. tion involves a microfilament-dependent constriction like a cleavage furrow, but is a distinct process ${ }^{47}$.

Results from studies of eggs and early embryos from a number of invertebrates with stereotypic cleavage patterns (including ctenophores, annelids and molluscs) emphasize the importance of cleavage Itself in distributing cytoplasm with distinct developmental potentlals in the embryo ${ }^{48}$. In many of these cases, peripheral cytoplasm can be observed to relocate with the progressing furrow. Unfortunately it is difficult to attribute the redistribution of developmental potential to furrow formation, rather than to the spindle structure, precleavage waves or other tightly linked events. Similar ingression of peripheral cytoplasm during cleavage in Xenopus ${ }^{39}$ (Fig. 1 le and $f$ ) is implicated in moving germ plasm deeper into vegetal blastomeres ${ }^{44}$. The extensive mixing of cytoplasm from different regions of the egg resulting from such ingression may well have other consequences in bringing together egg components originally localized in different regions. 


\section{Common mechanisms in domain establishment?}

Can any general conclusions be drawn from this examination of different egg cytoplasmic domains? Accumulations of mitochondria are found in several types of domain (e.g. ainphibian germ plasm and ascidian myoplasm), and ER accumulations have been described frequently in asters. We can speculate that the accumulation of organelles such as ER and mitochondria that affect cytoplasmic $\mathrm{Ca}^{2+}$ concentration and $\mathrm{pH}$ could help establish distinct 'physiological domains' inherited by specific blastomeres with different fates. Certain associations of organelles are probably favoured in eggs as the result of the activity of motor proteins that move different organelles over polarized frameworks of cytoskeletal filaments. However, there are many differences in the details of organelle-cytoskeleton associations between different eggs. Mitochondrial domains can form in microtubule asters, be linked to the actin cortex (e.g. in Phallusia), or be associated with intermediate filaments. Furthermore the composition and structure of the most widely found domain, germ plasm, varies from animal to animal and between different stages of development ${ }^{9}$. In Drosophila, mitochondria are preferentially active in the vicinity of germ plasm, even when they are not concentrated there ${ }^{53}$. Additionai markers for specific organelle subpopulations (differences within the ER for instance), as Wull as localized mRNAs and proteins, will be required before we can decide whether definable 'domain phenotypes' exist.

Once formed, egg domains tend to move as blocks rather than organelle by organelle. Displacement mechanisms thus rely on bulk flow cr movements of large structures rather than transport of individual components. Understanding the translocations will require both characterization of organelle-cytoskeleton interactions, and understanding of cellular fluld mechanics. The creation of new domains or the juxtaposition of pre-existing domains after translocation could allow developmentally important components from different parts of the egg to interact. In Xenopus, cytoplasmic movements associated with cortical rotation and cleavage may bring the products of vegetally localized growth factor mRNAs, originally attached to the oocyte cortex, to an equatorial region to be processed (perhaps proteolytically cleaved or secreted) ${ }^{50,51}$ by components originally localized in the animal yolk-free domain. Such ways of creating regional differences in embryos could be considered as 'intracellular induction'.

\section{References}

1 DING, D. and LIPSHITZ, H. D. (1993) BioEssays 15, 651-658

2 WILHELM, I. E. and VALE, R. D. (1993) J. Cell Biol. 123, 269-274

3 ELINSON, R. P. (1990) Curr. Opin. Cell Bioi. 2, 75-79

4 DAVIDSON, E. H. (1986) Gene Activity in Early Development (3rd eón), Academic Press
5 SLACK, J. M. W. (1991) From Egg to Embryo (2nd edn), Cambridge University Press

1. ST JOHNSTON, D. anu NUSSLEiN-VOLHARD, C. (i992) Cell 68, 201-219

7 ELINSON, R. P. and HOULISTON, E. (1990) Semin. Cell Biol. 1, 349-357

8 JEFFERY, W. R. and BATES, W. R. (1989) in The Molecular Biology of Fertilisation (Schatten, H. and Shatten, G., eds), pp. 342-367, Academic Press

9 MAHOWALD, A. P., ALLIS, C. D., KARRER, K. M., UNDERWOOD, E. M. and WARING, G. L. (1979) in Determinants of Spatial Organization (Subtelny, S. and Konigsberg, I. R., eds), pp. 127-146, Academic Press

10 LASKO, P. F. (1992) BioEssays 14, 507-512

11 EPHRUSSI, A. and LEHMANN, R. (1992) Nature 358, 387-392

12 WATANABE, M., ITOH, K., ABE, K., AKIZAWA, T., IKENISHI, K. and FURASAWA, M. (1992) Dev. Growth Differ. 34, 223-231

13 KOBAYASHI, S., AMIKURA, R. and OKADA, M. (1993) Science 260, 1521-1524

14 THEURKAUF, W. E., ALBERTS, B. M., JAN, Y. N. and JONCENS, A. (1993) Development 118, 1169-1180

15 IMOH, H. and MIYAZAKI, Y. (1984) Dev. Growth Differ. 26, 157-165

16 SWALLA, B. I., BADCETT, M. R. and JEFFERY, W. R. (1991) Development 111, 425-436

17 NISHIDA, H. (1992) Dev. Growth Differ. 34, 253-262

18 WHITAKER, M. and SWANN, K. (1993) Development 117, 1-12

19 JAFFE, L. A. and TERASAKI, M. (1993) Dev. Biol. 156, 566-573

20 SARDET, C. and CHANC, P. (1987) Cell Differ. 21, 1-19

21 SPUDICH, A. (1992) Curr. Top. Dev. Biol. 26, 9-21

22 BARTON, N. R., BONDER, E. M., FISHKIND, D. l., WARREN, R. H. and PRATT, M. M. (1992) J. Cell Science 103, 797-809

23 ELINSON, R. P. (1983) Dev. Blol. 100, 440-451

24 SPEKSNIIDER, J. E., SARDET, C. and JAFFE, L. F. (1990) /. Cell Biol. 110, 1589.-1598

25 SARDET, C., SPEKSNIIDER, J. E., TERASAKI, M. and CHANC, $P$. (1992) Development 115, 221-237

26 SPEKSNIJDER, J. E., TERASAKI, M., HACE, W. I., JAFFE, L. F. and SARDET, C. (1993) /. CEll Biol. 120, 1337-? 346

27 BATES, W. R. and JEFFERY, W. R. (1987) Dev Biol. 124, 65-76

28 SCHATTEN, H., SCHATTEN, C., MAZIA, D., BALCZON, R. and SIMERLY, C. (1986) Proc. Natl Acad. Sci. USA 83, 105-109

29 ALLEN, V. I. and VALE, R. D. (1991) /. Cell Biol. 113, 347-360

30 SARDET, C., SPEKSNIIDER, I. E., INOUE, S. and |AFFE, L. F. (1989) Development 105, 237-248

31 HOULISTON, E. and ELINSON, R. P. (1991) Development 112, 107-117

32 ELINSON, R. P. and PALECEK, J. (1993) Roux Arch. Develop. Biol. 202, 224-232

33 ZISCKIND, N. and ELINSON, R. P. (1990) Dev. Growth Differ. $32,575-581$

34 SATOH, H. and SHINACAWA, A. (1990) Dev. Growth Differ. 32, 609-617

35 VINCENT, I. P., OSTER, C. F. and GERHART, I. C. (1986) Dev. Biol. 113, 484-500

36 HOULISTON, E. and ELINSON, R. P. (1991) /. Cell Biol. 114, 1017-1028

37 DANILCHICK, M. V. and DENECRE, J. M. (1991) Development 111, 845-856

38 UBBELS, C. A., HARA, K., KOSTER, C. H. and KIRSCHNER, M. W. (1983) /. Embryol. Exp. Morph. 77, 15-37

39 DENECRE, I. M. and DANILCHICK, M. V. (1993) Dev. Biol. 160, 157-164

$40 \mathrm{IMOH}, \mathrm{H}$. (1984) Dev. Growth Differ. 26, 167-176 


\section{Acknowledgements \\ We thank W. Jeffery, E. Schierenberg and our colleagues in Villefranche ior their comments on the manuscript. \\ 41 SCHIERENBERG, E. and STROME, S. (1992) Semin. Dev. Biol. 3, 25-33 \\ 42 HIRD, S. N. and WHITE, J. G. (1993) i. Cell Biol. 121, 134j-i دj5 \\ 43 HARA, K. (1971) Wilhelm Roux Arch. Develop. Biol. 167, 183-186 \\ 44 SAVAGE, R. M. and DANILCHICK, M. V. (1993) Dev. Biol. 157, 371-382 \\ 45 HOULISTON, E., CARRE, D., JOHNSTON, J. A. and SARDET, C. (1993) Development 117, 75-87 \\ 46 DOHMEN, M. R. (1983) in Time, Space and Pattern in Embryonic Deveiopment (Jeffery, W. R. and Raff, R. F., eds), pp. 197-220, Alan Liss \\ The TGF- $\beta$ family and its composite receptors}

47 CONRAD, G. W., SCHANTZ, A. R. and PATRON, R. R. (1990) Anı. u. Rev. NY Acad. Sci. 582, 273-294

48 FREEMAN, G. (1983) in Time, Space and Pattern in Embryonic Development (Jeffery, W. R. and Raff, R. A., eds), pp. 171-196, Alan Liss

49 AKIYAMA, T. and OKADA, M. (1992) Development 115, 1175-1182

50 THOMSEN, G. H. and MELTON, D. A. Cell 74, 433-441

51 DALE, L., MATTHEWS, G. and COLMAN, A. (1993) EMBO J. 12, $4471-480$

Joan Massagué, Liliana Attisano and Jeffrey L. Wrana

In their search for regulators of animal growth and development,

biologists have often come upon members of the transforming growth factor $\beta$ (TGF- $\beta$ ) family and have realized that these are among the most versatile carriers of growth and differentiation signals. New evidence suggests that these factors signal through receptors with remarkable structures. Each receptor is a complex of two distantly related transmembrame serine/threonine kinases that are both essential for signalling. TGF- $\beta$ and related factors have at

their disposal a repertoire of such receptors, a feature that could account for their multifunctional nature.

The authors are at the Howard Hughes Medical Institute and Cell Biology and Genetics Program, Memorial SloanKettering Cancer

Center, New York, NY 10021, USA.
TGF- $\beta$ and related polypeptides regulate cell growth, differentiation, motility, organization and death. Some of them participate in setting up the basic body plan during early einbiyogenesis in mammais, frogs and flies, whereas others control the formation of cartilage, bone and sexual organs, suppress epithelial cell growth, foster wound repair, or regulate important immune and endocrine functions. The TGF- $\beta$ family is therefore viewed as one of the most influ. ential groups of growth and differentiation factors. Flucidating the mode of action of this family should unveil regulatory mechanisms of considerable interest In the past two years, this area has seen major advances, with the identification of various
TGF- $\beta$ receptors and downstream targets of the sigrals that they impart. This article focuses on the field's progress and directions.

\section{Structure of the factors}

Over two dozen TGF- $\beta$-related factors have been identified. The biologically active forms are disulphide-linked dimers containing subunits of 110-140 amino acids. The subunits are synthesized as the Cterminal portion of larger prerursors ${ }^{1,2}$ (Fig. 1a). After dimerization, the precursor is cleaved at a cluster of basic residues by a furin peptidase in the secretory pathway, which releases the bioactive domain. This domain may remain noncovalently associated with the propeptide, yielding a latent complex that is unable to bind receptor but can be activated later in the extracellular medlum.

All family members show sequence similarity to the prototype, TGF- 31 , particularly in the active domain, where the most conserved feature is the spacing of seven cysteines. The crystal structure of TGF- $\beta 2$ reveals that six of these cysteines form a rigid central structure known as the cystine knot ${ }^{3}$ (Fig. 1b). This singular motif is an eight amino acid ring closed by two cystine disulphide bonds and spanned by a third one. Four segments of twisted antiparallel $\beta$ sheets extend from the knot like two slightly curved fingers, and an $\alpha$-helix extends opposite to the fingers like the heel of a hand $d^{4,5}$. The remaining cysteine forms a disulphide bond with the corresponding cysteine in the other monomer.

The two monomers are oriented flat antiparallel to each other, and the inner surface of the fingers in one monomer forms hydrophobic contacts with the heel of the other ${ }^{4,5}$. These contacts might be sufficient to dimerize GDF-3 or GDF-9, two members of the TGF- $\beta$ family that lack the seventh cysiteine ${ }^{6}$. Certain unconserved residues at the fingertips and back of the hand could constitute receptor contact sites, 4.5 . TGF- $\beta$ s and activins, but not other family members, contain an extended $\mathrm{N}$-terminal region with two cysteines. In TGF- $\beta 2$, this region forms a short $\alpha$-helix 